\title{
Reisen Sie mit uns durchs „RADiversum“!
}

„Für die, die Vielfalt wirklich leben wollen.“ „Für die, die miteinander statt gegeneinander arbeiten wollen."

„Für die, die die Zukunft der Radiologie gestalten wollen."

„RADiversum“ - das ist der Podcast der Diversity-Kommission der Deutschen Röntgengesellschaft (DRG), der sich mit Vielfalt in der DRG und der Radiologie beschäftigt. Ab sofort können Sie in die vierte Folge unter dem Titel „Episode IV: Willkommenskultur: Respektvoll. Interessiert. Wertschätzend - der erste Eindruck zählt“ reinhören.

Gastgeberin ist in dieser Episode die Kommissionsgründerin Prof. Dr. Bettina Baeßler, die mit ihren 3 Gästen darüber spricht, was Willkommenskultur für die Medizin heißt, warum wir eine Willkommenskultur brauchen und wie wir diese umsetzen können.

Als Gäste begrüßt sie dabei Zuzana Blazek (KOFA - Kompetenzzentrum Fachkräftesicherung), Professor Lars Grenacher (Conradia Radiologie München und Vorsitzender der Arbeitsgemeinschaft Abdominal- und Gastrointestinaldiagnostik in der Deut-
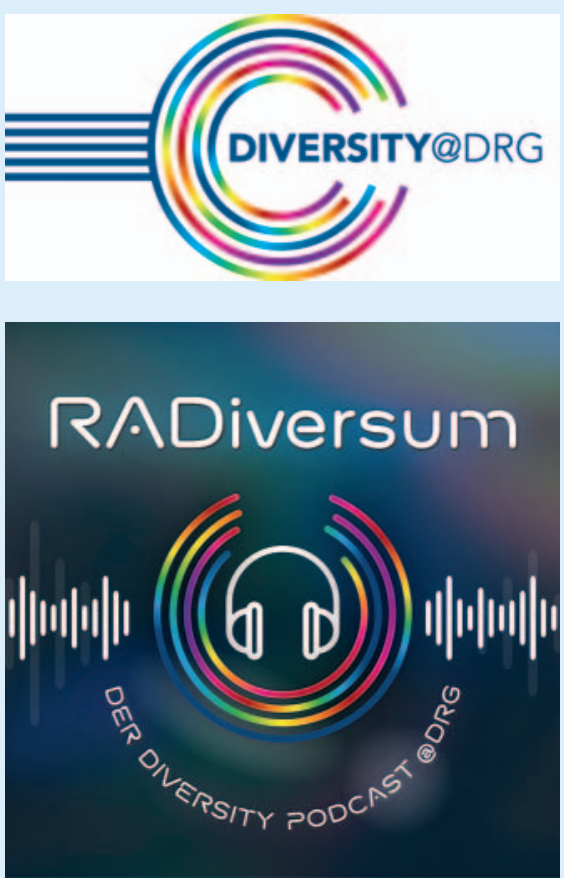

schen Röntgengesellschaft) und Professor Johannes Weßling (Leiter des Zentrums für Diagnostische und Interventionelle Radiologie, Neuroradiologie und Nuklearmedizin des Clemenshospitals, Raphaelsklinik und
EVK Münster und Vorstandsmitglied der Deutschen Röntgengesellschaft).

Sie möchten mehr über Diversity in der Deutschen Röntgengesellschaft erfahren? Dann hören Sie uns einfach auf www.diversity.drg.de oder überall dort, wo es Podcasts gibt: Spotify, iTunes, Amazon Music, Deezer und Google Podcasts.

Podcasthören alleine reicht Ihnen nicht aus und Sie haben Ideen oder möchten in der Kommission mitarbeiten? Dann schreiben Sie uns an diversity@drg.de! 